\title{
Role of nutritional factor menaquinone-7 in bone homeostasis and osteoporosis prevention
}

\author{
Masayoshi Yamaguchi* \\ Department of Hematology and Medical Oncology, Emory University School of Medicine, Atlanta, USA
}

\begin{abstract}
Bone homeostasis is mainly regulated by osteoblasts, osteocytes and osteoclasts. Osteoblasts promote bone formation and osteoclasts stimulate bone resorption. Bone loss with aging is due to decreased osteoblastic bone formation and increased osteoclastic bone resorption. Bone loss with various pathophysiologic states leads to osteoporosis. Nutrition and functional food factors may play a role in the prevention of bone loss. Menaquinone-7 (MK-7), a kind of vitamin $\mathrm{K}_{2}$, has been shown to reveal stimulatory effects on osteoblastic bone formation and suppressive effects on osteoclastic bone resorption in vitro. MK-7 stimulates protein synthesis (including osteocalcin and other protein molecules) in osteoblastic cells. MK-7 regulates the gene expression of various proteins, which are related to cellular functions in osteblastic and osteoclastic cells. MK-7 suppresses activation of NF- $\mathrm{BB}$ signaling pathways in osteoblasts and osteoclasts. Moreover, dietary intake of MK-7 has been shown to reveal potential preventive effects on bone loss in osteoporosis animal models and postmenopausal women. This review will discuss the role of dietary MK-7 in the prevention of osteoporosis.
\end{abstract}

\section{Introduction}

Bone homeostasis is mainly regulated by osteoblasts, osteocytes and osteoclasts. Osteoblasts promote bone formation and osteoclasts stimulate bone resorption [1]. Numerous pathological processes have been shown to stimulate bone resorption and suppress bone formation, leading to bone loss. Osteoporosis with bone loss is widely recognized as a major public health threat. The most dramatic expression of the disease is represented by bone fractures. Postmenopausal osteoporosis, which is induced by ovarian hormone deficiency in women after menopause, leads to severe bone destruction with increasing age [2]. Moreover, malnutrition or undernutrition is often observed in the elderly, and this nutritional state is more intense in patients with bone fracture than in the general aging population [3]. Deficiency in both micronutrients and macronutrients has been suggested to be important factors affecting on bone fracture in the osteoporotic elderly.

There is growing evidence that nutritional and functional food factors have been demonstrated to regulate bone homeostasis and reveal preventive and restorative effects on bone loss with various pathophysiologic conditions $[4,5]$. Nutritional factor vitamin $\mathrm{K}$, a fat-soluble vitamin, has been suggested to prevent bone fracture with osteoporosis. Vitamin $\mathrm{K}$ was originally identified as an essential cofactor for blood coagulation. Vitamin $\mathrm{K}$ is an essential in the posttranslational carboxylation of certain protein-bound glutamate residues of osteocalcin, which are converted into gamma $(\gamma)$-carboxy glutamate (Gla) by $\gamma$-carboxylase [6]. Osteocalcin is synthesized in osteobalsts. These Gla residues form calcium-binding sites that are essential for the activity of the proteins.

Menaquinone-7 (MK-7) is a kind of vitamin $\mathrm{K}_{2}$, which is greatly contained in fermented soybean (natto in Japanese). MK-7 has been shown to reveal osteogenic effects due to stimulating posteoblastic bone formation and to inhibiting osteoclastic bone resorption. Moreover, MK-7 has been shown to play a role in the prevention of bone loss in animal model for osteoporosis and human subjects [5]. This review will discuss recent advances regarding to the action of MK-7 in bone homeostasis and the role of dietary MK-7 intake in the prevention and treatment of osteoporosis.

\section{Vitamin $\mathrm{K}$ as nutritional factor}

Vitamin $\mathrm{K}$ is a fat-soluble vitamin. There are three types of vitamin $\mathrm{K}$ : vitamin $\mathrm{K}_{1}$ (phylloquinone), vitamin $\mathrm{K}_{2}$ (menaquinone), and vitamin $\mathrm{K}_{3}$ (menadione). Vitamin $\mathrm{K}_{1}$ is a sole compound, but vitamin $\mathrm{K}_{2}$ is a series of vitamers with multiisoprene units (one to four) at the 3-position of the naphthoquinone, which is classified according to the length of their aliphatic side chain and is designated as MK- $n$, where $n$ stands for the number of isoprenoid residues in that chain. Chemical structure of vitamin $\mathrm{K}$ is shown in Figure 1.

In food, the most important $\mathrm{K}$ vitamins are $\mathrm{K}_{1}$ that is found in green vegetables and some plant oils. The long-chain menaquinones (MK) including MK-7, MK-8, and MK-9 are present in fermented foods, notably cheese and natto. Natto, which is fermented soybeans, is popular food in Japan. Vitamin $\mathrm{K}_{1}$, MK-4 and MK-7 are used in food supplements. Since the molecular structures of vitamin $K_{1}$ and MK-4 are comparable, both contain 4 isoprenoid residues and 3 of which are saturated in vitamin $\mathrm{K}_{1}$ but contain a double bond in MK4. Their physico-chemical characteristics are closely similar (Figure 1). Menaquinones including MK-7 are much more hydrophobic. MK-7

Correspondence to: Dr. Masayoshi Yamaguchi, Department of Hematology and Medical Oncology, Emory University School of Medicine, 1365 C Clifton Road, NE, Atlanta, GA 30322, USA, E-mail: yamamasa1155@yahoo.co.jp

Key words: vitamin K2, menaquinone-7, osteoblastic bone formation, osteoclastic bone resorption, osteoporosis

Received: July 4, 2014; Accepted: July 17, 2014; Published: July 23, 2014 
has longer half-life times [7]. MK-7 is incorporated into low-density lipoproteins in the circulation of living body [8]. Vitamin $\mathrm{K}_{1}$ is the most common form of vitamin $\mathrm{K}$ in commercially available supplements. MK-7 is used as a supplement.

Bioavailability of MK-4 and MK-7 with nutritional doses has been examined in healthy Japanese women [9]. Serum levels of MK-7 absorbed by intestine were reached to maximal levels at 6 hours after intake, and its levels were detected up to 48 hours after intake with a single dose administration of MK-4 (420 $\mu$; $945 \mathrm{nmol})$ or MK-7 (420 $\mu \mathrm{g} ; 647 \mathrm{nmol}$ ) [9]. MK-4 was not detectable in the serum of all subjects at any time point, while MK-7 was significantly increased serum MK-7 levels in all subjects [9]. From these findings, it has been assumed that MK-4, which is present in food, may not contribute to the vitamin $\mathrm{K}$ status as estimated by serum vitamin K levels [9]. Intestinal absorption of vitamin $\mathrm{K}$ from diet gradually was declined with increasing age. Consequently, vitamin K deficiency may occur in elderly.

\section{Functional role of vitamin $\mathrm{K}$}

Vitamin $\mathrm{K}$, an essential factor for blood coagulation, is required for the carboxylation of Gla-proteins in the liver (coagulation factors) and extra-hepatic tissues, such as bone (osteocalcin) and arterial wall (matrix Gla-protein). Vitamin $\mathrm{K}$ is an important cofactor for the posttranslational carboxylation of certain protein-bound glutamate residues of osteocalcin, which are converted into $\gamma$-carboxy glutamate (Gla) by $\gamma$-carboxylase $[6,10]$. These Gla residues form calcium-binding sites that are essential for the activity of the proteins. During $\gamma$-glutamate carboxylation, vitamin $\mathrm{K}$ is oxidized into its epoxide form (KO) that is reconverted to vitamin $\mathrm{K}$ quinone $(\mathrm{K})$ by the enzyme vitamin $\mathrm{K}$ epoxide reductase (VKOR) [11]. Derivatives of 4-hydroxycoumarin (including warfarin and acenocoumarol) specifically inhibit VKOR, which prevents the recycling of vitamin $\mathrm{K}$ [11]. In this carboxylation process, glutamate residues are converted into $\gamma$-carboxyglutamate (Gla) [10]. Gla residues have a high affinity for calcium, which is an essential property of all Gla proteins. In addition, Gla-containing proteins are known as the blood coagulation factors II, VII, IX, and X, which are all synthesized in the liver [7]. Osteocalcin (synthesized in osteoblast) and matrix Gla protein (primarily synthesized in cartilage and in the vessel wall) are Gla proteins that are not related with blood clotting [7].

Coagulation factors are essential fully carboxylated under normal conditions. Dose-response effects of menaquinone intake on the carboxylation of the extra-hepatic Gla-proteins have been examined [12]. MK-7 supplementation with increasing doses increased the carboxylation of circulating osteocalcin and matrix Gla-protein in forty-two healthy men and women (aged between 18 and 45 years) that were received placebo capsules or MK-7 capsules with a daily dose of $10,20,45,90,180$ or $360 \mu \mathrm{g}$ [12]. MK-7 intake with nutritional doses improved the carboxylation of the extra-hepatic vitamin K-dependent proteins [12].

Vitamin $\mathrm{K}$ has been shown to contribute to bone health through its role as cofactor in the carboxylation of osteocalcin that is produced by osteoblasts. The effect of dietary intake of $45 \mu \mathrm{g}$ MK-7 on the circulating levels of undercarboxylated osteocalcin and carboxylated osteocalcin was examined in healthy prepubertal children [13]. Supplementation with MK-7 for 8 weeks was found to increase circulating concentrations of MK-7 and enhance osteocalcin carboxylation in healthy children $(n=55)$ [13]. The circulating concentrations of $\mathrm{K}_{1}, \mathrm{MK}-4$ and MK-7 in healthy women $(n=396)$ were also examined to ascertain whether each form of vitamin $\mathrm{K}$ is significantly associated with bone metabolism
Vitamin $\mathrm{K}_{1} \quad$ Phylloquinone

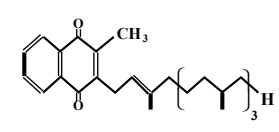

Vitamin $\mathrm{K}_{2} \quad$ Menaquinone-n

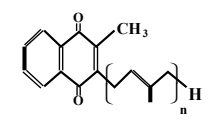

Vitamin $\mathrm{K}_{3}$

Figure 1: Chemical structure of Vitamin K.

[14]. Circulating concentrations of MK-7 were found to be the highest and MK- 4 was the lowest of the 3 vitamers in all age groups [14]. $\mathrm{K}_{1}$ and MK-7 were inversely correlated with undercarboxylated osteocalcin, but it was not observed that associations were not seen between nutritional basal concentration of MK-4 and undercarboxylated osteocalcin [14]. Plasma $\mathrm{K}_{1}$ or MK-7 concentration, which is required to minimize the undercarboxylated osteocalcin concentration, was shown to be the highest in the group aged over 70 years [14]. Circulating vitamin K concentrations in elderly people were needed to maintain at higher levels than those in young people to prevent bone loss and fracture [14].

Daily intake of about $100 \mu \mathrm{g}$ of vitamin $\mathrm{K}_{1}$ is recommended for the maintenance of hemostasis in adults [15]. Vitamin K deficiency was seen in the hospitalized patient including malabsorption syndromes (especially owing to chlestatic liver disease), antibiotic therapy, and renal insufficiency [15]. Pregnant women and their newborns presented a special risk category, because of poor placental transport and low concentrations of vitamin $\mathrm{K}$ in breast milk [15]. The Food and Drug Administration mandated that adult parenteral preparations should provide a supplemental amount of $150 \mu \mathrm{g}$ vitamin $\mathrm{K}_{1}$ per day [15]. This daily amount may be beneficial in preventing vitamin $\mathrm{K}$ deficiency [15].

\section{Role of MK-7 in bone homeostasis}

\section{Anabolic effects of MK-7 on bone metabolism}

Physiological roles of vitamin $\mathrm{K}_{2}$ are found in bone mineralization, arterial calcification, apoptosis, phagocytosis, growth control, chemotaxis and signal transduction. Especially, there is accumulating evidence for the roles of vitamin $\mathrm{K}$ in bone and vascular health. Vitamin $\mathrm{K}_{2}$ increased osteoblastic activity that enhances mineralization in vitro. Clinically, vitamin $\mathrm{K}_{2}$ maintained lumbar bone mineral density (BMD) and prevents osteoporotic fractures in patients with osteoporosis.

Anabolic effects of vitamin $\mathrm{K}$ on bone metabolism have been reported in several studies [15-20]. MK-4 increased the amount of osteocalcin and mineralization in cultured human osteoblasts [17]. MK-4 is essential for the $\gamma$-carboxylation of osteocalcin that are synthesized in osteoblasts of bone tissues [18]. Noncarboxylated osteocalcin cannot bind to hydroxyapatite in mineralized tissues [19]. MK-4 was also found to inhibit bone resorption and prevent bone loss in ovariectomized rats [20].

MK-7 contains very abundant in fermented soybean (natto), although it is only slight in other foods. Serum MK-7 concentration in women living in Tokyo, where fermented soybean is consumed, is about ten times higher than that of those living in Europe [21]. These differences may result from the intake of natto. Intake of MK-7 
through diet may be beneficial effect in bone metabolism. This author found that MK-7 reveals an anabolic effect on bone calcification in rat femoral tissues in vitro [22]. This was the first time finding that MK-7 reveals a direct anabolic effect on bone tissues. In addition, MK-7 was demonstrated to stimulate calcification in the femoral-metaphyseal tissues obtained from young and aged rats in vitro [23]. Action of MK-7 on bone calcification revealed the same effect as compared with that of MK-4 [23]. MK-7 is partially converted to MK-4 in the body. Vitamin $\mathrm{K}_{2}$ may be important in maintaining bone healthy $[24,25]$.

Osteocalcin, which is a bone matrix protein, is synthesized in osteoblasts with vitamin $\mathrm{K}$ dependent in the bone tissues. The fraction newly synthesized by osteoblasts is released into circulation. Therefore, the circulating levels of osteocalcin are considered sensitive markers of bone formation [26,27]. Among various types of osteocalcins, fully carboxylated osteocalcin has a high affinity to calcium and/or hydroxyapataite and may play an important role in maintaining BMD and reducing the incidence of fractures through incremental bone formation $[26,27]$.

Several studies in adults suggested a beneficial role for vitamin $\mathrm{K}$ in bone mineral metabolism and bone fracture prevention [14]. Poor vitamin $\mathrm{K}$ status may lead to production of undercarboxylated osteocalcin [28]. In the healthy adult population, osteocalcin was carboxylated to a variable extent, suggesting that the intake of dietary vitamin $\mathrm{K}$ is often insufficient for carboxylation of osteocalcin. Elevated undercarboxylated osteocalcin and fracture risk were occurred in postmenopausal women [14].

Patients with hip fracture showed lower vitamin $\mathrm{K}_{1}$ levels [25]. Lower levels of vitamin $\mathrm{K}_{1}$ and vitamin $\mathrm{K}_{2}$ were found in the serum obtained from elderly patients after a hip fracture [29]. A low vitamin $\mathrm{K}_{1}$ intake is one of the risk factors in hip fracture. Higher vitamin $\mathrm{K}_{1}$ levels than the current recommendation for coagulation parameters may be required for carboxylation of osteocalcin [30]. The fractions of osteocalcin with a high affinity to hydroxyapatite were increased following vitamin $\mathrm{K}_{1}$ administration in association with a reduction in urinary calcium excretion [31]. A daily vitamin $K_{1}$ supplement of 80 $\mu \mathrm{g}$ was suitable to reaching a premenopausal carboxylated osteocalcin/ total osteocalcin ratio [32]. Vitamin K deficiency may be responsible for reduced carboxylation of osteocalci. This may be one of the risk factors in low bone mass resulting in fragility fractures. Intake of dietary vitamin $\mathrm{K}$ may ameliorate undercarboxylation of osteocalcin in the elderly with osteoporosis and is potential beneficial effect on bone.

\section{MK-7 stimulates osteoblastic bone formation}

MK-7, which was isolated from natto, has been shown to stimulate bone calcification in the femoral tissues obtained from normal young and aged rats in vitro [22]. Culture with MK-7 $\left(10^{-6}\right.$ or $\left.10^{-5} \mathrm{M}\right)$ caused a significant increase in biochemical components (alkaline phosphatase activity, DNA and calcium contents) in the femoral-cortical and -trabecular tissues obtained from aged rats in vitro [23]. Such an effect of MK-7 was also enhanced in the presence of genistein [23]. Anabolic effect of MK-7 in the bone tissues was based on newly synthesized protein components in vitro [23]. Moreover, MK-7 caused a significant increase in alkaline phosphatase activity, protein (including osteocalcin) and DNA contents in osteoblastic MC3T3-E1 cells in vitro [33]. The effect of MK-7 in osteoblastic cells was completely depressed in the presence of protein inhibitor. Thus, MK-7 has been demonstrated to stimulate osteoblastic bone formation due to increasing protein synthesis [33].
The effects of MK-7 on various gene expressions, which are related to osteoblastic function, have been shown in osteoblastic MC3T3E1 cells in vitro [34]. MK-7 did not have effects on the proliferation of osteoblastic cell cultured for 4 days [34]. However, cell proliferation was suppressed in osteoblastic cells cultured with MK-7 for 10 days [34]. MK-7 stimulated the gene expression of osteocalcin, osteoprotegerin, the receptor activator of the NFKB ligand (RANKL) and RANK in osteoblastic cells [34]. MK-7 may regulate gene expressions in osteoblastic MC3T3-E1 cells [34].

Osteoblast is differentiated from bone marrow mesenchymal stem cells. MK-7 enhanced vitamin $\mathrm{D}_{3}$-induced gene expression of osteocalcin in mesenchymal stem cells [35]. Among genes related to cell growth and differentiation, a specific effect of MK-7 was found in growth differentiation factor-10 and insulin-like growth factor 1, and the latter being also involved in the induction of vascular endothelial growth factors [35].

Moreover, MK-7 has been shown to be a transcription regulator of bone-specific genes that act through steroid and xenobiotic receptors (SXRs), which stimulates transcription process of osteoblastic markers [36].

\section{MK-7 suppresses osteocalstic bone resorption}

MK-7 has been demonstrated to have suppressive effects on oteoclastic bone resoption in vitro [37]. MK-7 was found to reveal suppressive effects on the decrease in calcium content in rat femoral tissues, which are induced after culture with bone-resorbing factors including parathyroid hormone $(\mathrm{PTH})$ and prostaglandin $\mathrm{E}_{2}\left(\mathrm{PGE}_{2}\right)$, demonstrating its suppressive effects on bone resorption in vitro [37]. Suppressive effects of MK-7 on bone resorption were partly involved in inhibition for PTH- or $\mathrm{PGE}_{2}$-stimulated increase in lactic acid, which is produced by medium glucose consumption in the bone tissues in vitro [37].

Osteoclastic cells are formed from bone marrow cells in the presence of bone-resorbing factors (PTH, $\mathrm{PGE}_{2}$ and other) [37]. MK-7 $\left(10^{-8}-10^{-5} \mathrm{M}\right)$ was found to suppress PTH- or $\mathrm{PGE}_{2}$-induced increase in osteoclast-like cell formation in mouse bone marrow cell culture in vitro [37]. MK-7 revealed more potent-suppressive effects at later stage of the differentiation of bone marrow cells. MK-7 suppressed osteoclastogenesis after culture with phorbol 12-myristate 13-acetate (PMA), an activator of protein kinase C [37]. MK-7 may suppress activation of protein kinase $C$ signaling [37]. However, MK-7 did not inhibit cyclic AMP-dependent signaling-stimulated osteoclastogenesis in bone marrow cell culture in vitro [37].

The effect of MK-7 on mature osteoclasts isolated from rat femoral tissues has also been examined [37]. MK-7 was found to decrease in the number of mature osteoclasts in vitro, inducing cell apoptosis [37]. This effect was partly mediated through suppressive action of MK-7 for the pathways of $\mathrm{Ca}^{2+}$ - and cyclic AMP-dependent signaling [37].

\section{MK-7 suppresses pathway of NF- $\mathrm{kB}$ signal transduction}

MK-7 stimulated osteoblastic bone formation and suppresses osteoclastic bone resorption. MK-7 increased protein synthesis including osteocalcin and activates $\gamma$-carboxylase in osteoblastic cells. Moreover, MK-7 was found to suppress activation of NF- $\mathrm{KB}$ signaling in both osteoblastogenesis and osteoclastogenesis. Activation of NF$\kappa \mathrm{B}$ signal transduction pathway is essential for osteoclast formation. Also, NF- $\mathrm{\kappa B}$ signaling potently antagonizes osteoblast differentiation in osteoblastic cells [38]. Cytokine-induced NF- $\kappa \mathrm{B}$ activation inhibits 
differentiation of pre-osteoblastic cells and stimulates the formation of osteoclasts [38]. MK-7 was found to restore depression by TNF- $\alpha$ of Smad signaling induced by either TGF- $\beta$ or BMP-2 [38]. MK-7 further antagonized receptor activator of NF- $\mathrm{KB}$ (RANK) ligand (RANKL)induced NF- $\kappa \mathrm{B}$ activation in osteoclast precursors [38]. MK-7 stimulated I $\mathrm{B}$ mRNA expression [38]. Thus MK-7 down-regulated basal and cytokine-induced NF- $\kappa \mathrm{B}$ activation, and this action was a $\gamma$-carboxylation-independent manner [38]. These findings provide a novel mechanism of vitamin $\mathrm{K}_{2}$, which stimulates osteblastic bone formation and suppresses osteoclastic bone resorption, as shown in Figure 2 .

\section{Dietary MK-7 prevents bone loss in animal models}

MK-7 increases bone mass due to stimulating osteoblastic bone formation and inhibiting osteoclastic bone resorption, suggesting that the vitamin $\mathrm{K}_{2}$ has a preventive effect on osteoporosis. Preventive effects of dietary MK-7 on bone loss have been shown using ovariectomized (OVX) rats, animal models for postmenopausal osteoporosis [39]. MK-7 was found to have preventive effects on OVX-induced decrease in the femoral dry weight and calcium content [39]. In separate experiments, OVX rats were given experimental diets containing fermented soybeans (natto; including MK-7, $9.4 \mu \mathrm{g} / 100 \mathrm{~g}$ diet) with or without added MK-7 (37.6 $\mu \mathrm{g} / 100 \mathrm{~g}$ diet) for 77 days [39]. Dietary MK-7 prevented OVX-induced decreases in the femoral dry weight and femoral calcium content [39]. Thus dietary MK-7 was demonstrated to reveal preventive effects on bone loss in menopausal osteoporosis model animals in vivo.

The effect of prolonged intake of dietary MK-7 on bone loss in OVX rats was also found [40]. Dietary MK-7 (9.4 $\mu \mathrm{g} / 100 \mathrm{~g}$ diet) with or without supplemental MK-7 (containing 14.1 or $18.8 \mu \mathrm{g} / 100 \mathrm{~g}$ diet) was given to OVX rats for 150 days [40]. Feeding produced an elevation of serum concentration of MK-7 in OVX rats [40]. Feeding of MK-7 (18.8 $\mu \mathrm{g} / 100 \mathrm{~g}$ diet) prevented decreases in serum $\gamma$-carboxylated osteocalcin concentration, femoral dry weight, femoral calcium content, and mineral density that are induced by OVX [40]. Prolonged intake of dietary MK-7 prevented OVX-induced bone loss. Dietary MK-7 may be useful in the prevention of osteoporosis.

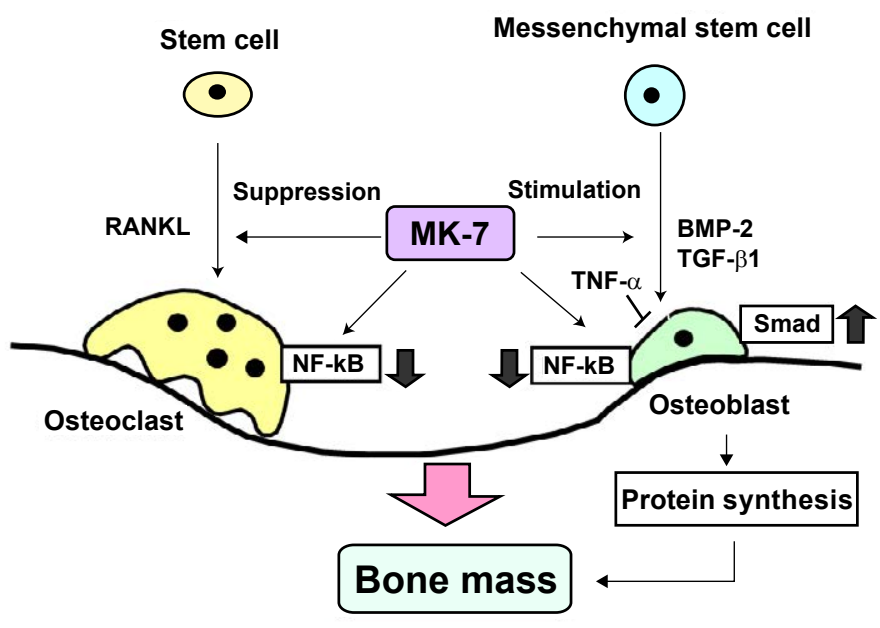

Figure 2: Cellular mechanism by which menaquinone-7 (MK-7) stimulates osteoblastic bone formation and suppresses osteoclastic bone resorption. MK-7 suppresses NF- $\kappa B$ signaling pathways, which are activated by stimulation of TNF- $\alpha$ or RANKL, in osteoblasts and osteoclasts. In addition, MK-7 stimulates protein synthesis (including osteocalcin and other protein molecules) in osteoblastic cells, and it may regulate the gene expression of various proteins, which are related to cellular functions in osteblastic and osteoclastic cells.
Combination of nutritional factors may have additive or synergistic effects in the prevention of bone loss with increasing age. Interestingly, the anabolic effect of MK-7 on bone components was found to synergistically enhance with combination of zinc in rats in vivo [41]. Supplemental intake with combination of MK-7 and zinc may be potential in the prevention and treatment of osteoporosis with increasing age.

\section{Effect of supplemental MK-7 on bone loss in postmenopausal women}

Fermented soybeans (natto), which contain a large amount ofMK-7, may help in the prevention of osteoporosis. Epidemiologic data suggested that intake of natto may play a preventive role for osteoporosis [21]. Moreover, it was demonstrated that prolonged intake of natto brings an increase in MK-7 and a corresponding elevation of $\gamma$-carboxylated osteocalcin in the serum of normal human individuals (forty-eight volunteers; 45 men and 3 women) $[42,43]$. Serum MK-7 was not found in normal individuals without dietary natto intake. Increases in serum MK-7 and $\gamma$-carboxylated osteocalcin concentrations were observed for 14 days after the start of dietary natto intake containing MK-7 1295 or $1730 \mu \mathrm{g} / 100 \mathrm{~g}$ diet [43]. Appropriate amount of dietary MK-7 may bring benefic effects on bone mineralization in human individuals. Supplemental intake of MK-7 may be a useful tool in the prevention and treatment of bone loss with aging.

The possibility of an association between habitual natto intake and bone mineral density (BMD) and BMD change was studied in healthy Japanese women who participated in a large representative cohort study (Japanese Population-based Osteoporosis Study: JPOS study) [44]. BMD was measured at the spine, hip and forearm in 944 women (20-79 years old) at baseline and at a follow-up conducted 3 years later [44]. The total hip BMD was found to elevate with increasing of natto intake in the postmenopausal women [44]. In addition, there were observed significant positive associations between natto intake and the rates of changes in BMD at the femoral and at the distal third of the radius in the postmenopausal women [44]. Dietary natto intake was suggested to prevent postmenopausal bone loss through the effects of menaquinone 7 that are more abundant in natto than in other soybean products.

Supplementation with 3-year high-dose vitamin $\mathrm{K}_{1}$ (phylloquinone) and $\mathrm{K}_{2}$ (MK-4) has been shown to improve bone health after menopause [45]. Intake of MK-7 improved vitamin $\mathrm{K}$ status and to decrease the age-related decline in BMD at the lumbar spine and femoral neck, when healthy postmenopausal women $(n=244)$ were received for 3 years placebo or MK-7 (180 $\mu \mathrm{g}$ MK-7/day) capsules [45]. Intake of MK-7 was also found to increase bone strength and prevent the loss in vertebral height of the lower thoracic region at the mid-site of the vertebrae [45]. MK-7 supplements may prevent bone loss in postmenopausal women.

Moreover, the effect of dairy products enriched with calcium, vitamin $\mathrm{D}_{3}$, and vitamin $\mathrm{K}_{1}$ or MK-7 on parameters of bone metabolism was shown in postmenopausal women following a 12-month intervention [46]. Postmenopausal women received fortified dairy products providing either daily $800 \mathrm{mg}$ of calcium and $10 \mu \mathrm{g}$ of vitamin $\mathrm{D}_{3}(\mathrm{CaD})$ or daily $100 \mu \mathrm{g}$ of either vitamin $\mathrm{K}_{1}(\mathrm{CaDK} 1)$ or MK-7 (CaDK2) [46]. Increase in the serum 25-hydroxyvitamin $\mathrm{D}_{3}$ levels was observed in all intervention groups [46]. Decrease in serum undercarboxylated osteocalcin to osteocalcin ratio and urine deoxypyridinoline levels in both the $\mathrm{CaDK} 1$ and $\mathrm{CaDK} 2$ groups was also seen as compared to 
the $\mathrm{CaD}$ and control groups [46]. Moreover, significant increases in BMD in total-body and lumbar spine were observed only for CaDK1 and CaDK2 [46]. This study showed more favorable changes in bone metabolism and bone mass with supplementation of vitamin $\mathrm{K}$ [46]. Thus supplemental MK-7 may have benefic effects in the prevention and treatment of bone loss in postmenopausal women.

\section{Prospect}

Vitamin $\mathrm{K}_{2}$, which was discovered as blood coagulation factor, may play multifunctional roles in the living body. Vitamin $\mathrm{K}_{2}$ plays an essential role as co-factor of $\gamma$-carboxylase that converted glutamate residues of osteocalcin into $\gamma$-carboxyglutamate, suggesting its role in bone metabolism. In this review, the role of MK-7 in bone homeostasis has been focused. MK-7 stimulates osteoblastic bone formation and inhibits osteoclastic bone resorption. This action of MK-7 has been demonstrated to mediate through the pathways of $\mathrm{Ca}^{2+}$ - and cyclic AMP-dependent signaling and the antagonizing cytokine-induced NF$\kappa \mathrm{B}$ activation in a $\gamma$-carboxylation-independent manner. Moreover, MK-7 regulates a transcription of bone-specific genes that act through steroid and xenobiotic receptors to promote the expression of osteoblastic marker proteins, and it also stimulates the synthesis of various proteins including osteocalcin in bone cells. Further studies remains to be elucidated molecular and cellular mechanisms of MK-7.

Several studies have demonstrated that dietary intake of MK-7 has benefit effects to prevent bone loss and bone fracture in normal postmenopausal women. MK-7 may be useful in the prevention and amelioration of osteoporosis. Moreover, MK-7 may suppress bone loss in various disease states including inflammation, obesity, diabetes, and cancer bone metastastasis. Drugs, which are used clinically in the treatment of osteoporosis, are mainly based on the action of osteoclastic bone resorption. Clinical compounds that stimulate bone formation are under development. MK-7 will be expected as a potential osteogenic factor in the treatment of osteoporosis.

\section{Acknowledgements}

The author was partly supported by Awards of the Mishima Kaiun Memorial Foundation (Japan), the Senji Miyata Foundation (Japan), and the Japan Society for Biomedical Research on Trace Elements. This study was also supported by the Foundation for Biomedical Research on Bone Health and Nutrients, Japan.

\section{References}

1. Raggatt LJ, Partridge NC (2010) Cellular and molecular mechanisms of bone modeling. J Biol Chem 285: 25103-25108. [Crossref]

2. Weitzmann MN, Pacifici R (2006) Estrogen deficiency and bone loss: an inflammatory tale. J Clin Invest 116: 1186-1194. [Crossref]

3. Bonjour J-P, Schurch M-A, Rizzori R (1996) Nutritional aspects of hip fracture. Bone 18: 1395-1445. [Crossref]

4. Yamaguchi M (2010) Role of nutritional zinc in the prevention of osteoporosis. Mol Cell Biochem 338: 241-254. [Crossref]

5. Yamaguchi M (2013) Biomedical Osteoporosis Treatment. Nova Science Publishers, Inc., New York, USA.

6. Price PA (1985) Vitamin K-dependent formation of bone gla protein (osteocalcin) and its function. Vitam Horm 42: 65-108. [Crossref]

7. Schurgers LJ, Vermeer C (2000) Determination of phyloquinone and menaquinones in food: effect of food matrix on circulating vitamin $\mathrm{K}$ concentrations. Haemostasis 30 : 298-307. [Crossref]

8. Schurgers LJ, Vermeer C (2002) Differential lipoprotein transport pathways of K-vitamins in healthy subjects. Biochim Biophys Acta 1570: 27-32. [Crossref]
9. Sato T, Schurgers LJ, Uenishi K (2012) Comparison of menaquinone-4 and menaquinone-7 bioavailability in healthy women. Nutr J 11: 93.

10. Shearer M J (2009) Vitamin K in parenteral nutrition. Gastroenterology 137: S105-S118.

11. Schurgers LJ, Teunissen KJF, Hamulyak K, Knapen MHJ, Vik H, et al. (2007) Vitamin $\mathrm{K}$-containing dietary supplements: comparison of synthetic vitamin $\mathrm{K}_{1}$ and nattoderived menaquinone-7. Blood 109: 3279-3283. [Crossref]

12. Theuwissen E, Cranenburg EC, Knapen MH, Magdeleyns EJ, Teunissen KJ, et al (2012) Low-dose menaquinone-7 supplementation improved extra-hepatic vitamin $\mathrm{K}$ status, but had no effect on thrombin generation in healthy subjects. $\mathrm{Br} J$ Nutr 108:1652-1657. [Crossref]

13. van Summeren MJH, Braam LAJL, Lilien MR, Schurgers LJ, Wietse Kuis W, et al. (2009) The effect of menaquinone-7 (vitamin $\mathrm{K}_{2}$ ) supplementation on osteocalcin carboxylation in healthy prepubertal children. BrJ Nutr 102: 1171-1178. [Crossref]

14. Tsugawa N, Shiraki M, Suhara Y, Kamao M, Tanaka K, et al. (2006) Vitamin K status of healthy Japanese women: age-related vitamin $\mathrm{K}$ requirement for $\gamma$-carboxylation of osteocalcin. Am J Clin Nutr 83: 380-386. [Crossref]

15. Shearer MJ (2000) Role of vitamin K and Gla proteins in the pathophysiology of oetoporosis and vascular calcification. Cur Opin Clin Nutr Metab Care 3: 433-438. [Crossref]

16. Iwamoto J, Sato Y, Takeda T, Matumoto H(2009) High-dose vitamin K supplementation reduces fracture incidence in postmenopausal women: a review of the literature. Nutr Res 29: 221-228. [Crossref]

17. Koshihara Y, Hoshi K, Shiraki M (1992) Enhancement of mineralization of human osteoblasts by vitamin K2 (menaquinone-4). J Clin Exp Med 161: 439-440.

18. Hauschka PV, Lian JB, Gallop PM (1975) Direct identification of the calcium-binding amino acid, $\gamma$-carboxyglutamate, in mineralized tissue. Proc Natl Acad Sci USA 72 : 3925-3929. [Crossref]

19. Hauschka PV, Carr SA (1982) Calcium-dependent $\alpha$-helical structure in osteocalcin Biochemistry 21: 2538-2547.

20. Akiyama Y, Hara K, Ohkawa I, Tajima, T (1993) Effects of menaterenone on bone loss induced by ovariectomy in rats. Jpn J Pharmacol 62: 145-153. [Crossref]

21. Hosoi T (1996) Recent progress in treatement of osteoporosis. Nippon Ronnen Igaku Zasshi 33: 240-244. [Crossref]

22. Ehara Y, Takahashi H, Hanahisa Y, Yamaguchi M (1996) Effect of vitamin K2 (menaquinone-7) on bone metabolism in the femoral-metaphyseal tissues of normal and skeletal-unloaded rats: enhancement with zinc. Res Exp Med 196: 171-178. [Crossref]

23. Yamaguchi M, Uchiyama S, Tsukamoto Y (2002) Stimulatory effect of menaquinone-7 on bone formation in elderly female rat femoral tissues in vitro: Prevention of bone deterioration with aging. Int J Mol Med 10: 720-733. [Crossref]

24. Knapen MHJ, Hamulyak K, Vermeer C (1989) The effect of vitamin K supplementation on circulating osteocalcin (bone gla protein) and urinary calcium excretion. Ann Intern Med 111: 1001-1005. [Crossref]

25. Hart JP, Sheaver MJ, Klenerman L, Catterall A, Reeve J, et al. (1985) Electrochemical detection of depressed circulating levels of vitamin $\mathrm{K} 1$ in osteoporosis. J Clin Endocrinol Metab 60: 1268-1269. [Crossref]

26. Delmas PD (1993) Biochemical markers of bone turnover. 1. Theoretical considerations and clinical use in osteoporosis. Am J Med 95 (suppl 5A): 11-16. [Crossref]

27. Miki T, Nakatsuka K, Naka H, Kitatani K, Saito S, et al. (2003) Vitamin K2 (menaquinone 4) reduces serum undercarboxylated osteocalcin level as early as 2 weeks in elderly women with established osteoporosis. J Bone Miner Metab 21: 161165. [Crossref]

28. Koshihara Y, Hosoi K (1997) Vitamin K2 enhances osteocalcin accumulation in the extracellular matrix of human osteoblasts in vitro. J Bone Miner Res 12: 431-438. [Crossref]

29. Hodges SJ, Akesson K, Vergnaud P, Obrant K, Delmas PD (1993) Circulating levels of vitamin $\mathrm{K} 1$ and $\mathrm{K} 2$ decreased in elderly woman with hip fracture. $J$ Bone Miner Res 8: 1241-1245. [Crossref]

30. Binkley NC, Krueger DC, Engelke JA, Foley AL, Suttie JW (2000) VitaminK supplementation reduces serum concentrations of under-gamma-carboxylated osteocalcin in healthy young and elderly adults. Am J Clin Nutr 72: 1523-1528. [Crossref]

31. Knapen MHJ, Jie KSG, Hamulyak K, Vermeer C (1993) VitaminK-induced changes 
in markers for osteoblast activity and urinary calcium loss. Calcif Tissue Int 53: 81-85. [Crossref]

32. Schaafsma A, Muskiet FA, Storm H, Hofstede GJ, Pakan I, et al. (2000) Vitamin D3 and vitamin K1 supplementation of Dutch postmenopausal women with normal and low bone mineral densities: effects on serum 25-hydroxyvitamin D and carboxylated osteocalcin. Eur J Clin Nutr 54: 626-631. [Crossref]

33. Yamaguchi M, Sugimoto E, Hachiya S (2001) Stimulatory effect of menaquinone-7 (vitamin K2) on osteoblastic bone formation in vitro. Mol Cell Biochem 223: 131-137. [Crossref]

34. Katsuyama H, Otsuki T, Tomita M, Fukunaga M, Fukunaga T, et al. (2005) Menaquinone-7 regulates the expressions of osteocalcin, OPG, RANKL and RANK in osteoblastic MC3T3-E1 cells. Int J Mol Med 15: 231-236. [Crossref]

35. Giqante A, Bruqe F, Cecconi S, Manzotti S, Littarru GP, et al. (2012) Vitamin MK-7 enhances vitamin D3-induced osteogenesis in hMSCs: modulation of key effectors in mineralization and vascularization. J Tissue Eng Regen Med. [Crossref]

36. Tabb MM, Sun A, Zhou C, Grun F, Errandi J, Romero K, Pham H, Inoue S, Mallick $\mathrm{S}$, Lin, Forman BM, Blumberg B (2003) Vitamin K2 regulation of bone homeostasis is mediated by the steroid and xenobiotic receptor SXR. J Biol Chem 278: 43919-43927. [Crossref]

37. Yamaguchi M, Ma ZJ (2001) Inhibitory effect of menaquinone-7 (vitamin K2) on osteoclast-like cell formation and osteoclastic bone resorption in rat bone tissues in vitro. Mol Cell Biochem 228: 39-47. [Crossref]

38. Yamaguchi M, Weitzmann MN (2011) Vitamin K2 stimulates osteoblastogenesis and suppresses osteoclastogenesis by suppressing NF-B activation. Int J Mol Med 27: 3-14. [Crossref]

39. Yamaguchi M, Taguchi H, Gao YH, Igarashi A, Tsukamoto Y (1999) Effect of vitamin $\mathrm{K} 2$ (menaquinone-7) in fermented soybean (natto) on bone loss in ovariectomized rats. J Bone Miner Metab 17: 23-29. [Crossref]
40. Yamaguchi M, Kakuda H, Gao YH, Tsukamoto Y (2000) Prolonged intake of fermented soybean (natto) diets containing vitamin K2 (menaquinone-7) prevents bone loss in ovariectomized rats. J Bone Miner Metab 18: 71-76. [Crossref]

41. Ma ZJ, Igarashi A, Yamakawa K, Yamaguchi M (2001) Enhancing effect of zinc and vitamin K2 (menaquinone-7) on bone components in the femoral tissues of female elderly rats. $J$ Health Sci 47: 40-45.

42. Tsukamoto Y, Ichise H, Yamaguchi M (2000) Prolonged intake of dietary fermented soybeans (natto) with the reinforced vitamin K2 (menaquinone-7) enhances circulating $\gamma$-carboxylated osteocalcin concentration in normal individuals. J Health Sci 46: 317 321

43. Tsukamoto Y, Ichise H, Kakuda K, Yamaguchi M (2000) Intake of fermented soybean (natto) increases circulating vitamin $\mathrm{K} 2$ (menaquinone-7) and $\gamma$-carboxylated osteocalcin concentration in normal individuals. J Bone Miner Metab 18: 216-222. [Crossref]

44. Ikeda Y, Iki M, Morita A, Kajita A, Kagamimori S, et al. (2006) Intake of fermented soybeans, natto, is associated with reduced bone loss in postmenopausal women: Japanese population-based osteoporosis (JPOS) study. J Nutr 136: 1323-1328. [Crossref]

45. Knapen MHJ, Drummen NE, Smit E, Vermeer C, Theuwissen E (2013) Threeyear low-dose menaquinone-7 supplementation helps decrease bone loss healthy postmenopausal women. Osteoporosis Int 24: 2499-2507. [Crossref]

46. Kanellakis S, Moschonis G, Tenta R, Schaafsma A, van den Heuvel EGHM, et al (2012) Changes in Parameters of Bone Metabolism in Postmenopausal Women Following a 12-Month Intervention Period Using Dairy Products Enriched with Calcium, Vitamin D, and Phylloquinone (Vitamin K1) or Menaquinone-7 (Vitamin K2): The Postmenopausal Health Study II. Calcif Tissue Int 90: 251-262. [Crossref]

Copyright: (C2014 Yamaguchi. This is an open-access article distributed under the terms of the Creative Commons Attribution License, which permits unrestricted use, distribution, and reproduction in any medium, provided the original author and source are credited. 